\title{
The cytochrome bd quinol oxidase in Escherichia coli has an extremely high oxygen affinity and two oxygen-binding haems: implications for regulation of activity in vivo by oxygen inhibition
}

\author{
Rita D'mello, ${ }^{1}$ Susan Hill² $†$ and Robert K. Poole ${ }^{1}$ \\ Author for correspondence: Robert K. Poole. Tel: +44 171333 4275. Fax: +44 1713334500. \\ e-mail: udbs065@bay.cc.kcl.ac.uk
}

1 Division of Life Sciences, King's College London, Campden Hill Road, London W8 7AH, UK

2 Nitrogen Fixation Laboratory, John Innes Centre, University of Sussex, Brighton BN1 9RQ, UK

\begin{abstract}
Cytochrome bd is a respiratory oxidase in Escherichia coli and many other bacteria. It contains cytochromes $b_{558}, b_{595}$ and $d$ as redox centres, and is thus unrelated to the haem-copper super-family of terminal oxidases. The apparent affinities $\left(K_{m}\right)$ for oxygen uptake by respiring cells and membranes from a mutant lacking the alternative oxidase cytochrome bo' were determined by deoxygenation of oxyleghaemoglobin as a sensitive reporter of dissolved oxygen concentration. Respiration rates were maximal at oxygen concentrations of 25-50 nM, but the kinetics were complex and indicative of substrate (i.e. oxygen) inhibition. $K_{m}$ values were in the range 3-8 $\mathrm{nM}$ (the lowest recorded for a respiratory oxidase), and $K_{i}$ values between 0.5 and 1.8 $\mu \mathrm{M}$ were obtained. Low temperature photodissociation of anoxic, COligated membranes confirmed the absence of cytochrome bo' and revealed a high-spin b-type cytochrome identified as cytochrome $b_{595}$ of the cytochrome bd complex. Photodissociation in the presence of oxygen revealed binding of a ligand (presumably oxygen) to cytochrome $b_{595}$ at a rate much greater than that of $\mathrm{CO}$ binding, and formation of the oxygenated form of cytochrome $d$. The results confirm that both high-spin haems in the cytochrome bd complex bind $\mathrm{CO}$ and demonstrate that oxygen can also react with both haems. Substrate inhibition of oxidase activity, in addition to transcriptional regulation of oxidase synthesis, may play a crucial role in the regulation of partitioning of electron flux between the cytochrome bd- and bo'-terminated respiratory pathways.
\end{abstract}

Keywords: Escherichia coli, respiratory electron flux, quinol oxidases, oxygen affinity, cytochromes

\section{INTRODUCTION}

In bacteria, a single terminal respiratory oxidase catalysing the reduction of oxygen (as in mitochondria) is the exception, rather than the rule (Poole, 1983). Instead, the presence of branched respiratory chains, terminating in up to four different oxidases, has been claimed (e.g. Kitts \& Ludwig, 1994). These multiple branched systems raise several important questions: in particular, what is the function of such apparent redundancy, how is electron

†Present address: Biology Building, University of Sussex, Brighton BN1 9QG, UK. flux between the branches regulated, and are all the putative oxidases (frequently identified only on the basis of $\mathrm{CO}$ difference spectra or nucleotide sequence data) actually functional?

In Escherichia coli, two oxygen-reactive haems, cytochromes 0 and $d$, were clearly identified by photochemical action spectroscopy (Castor \& Chance, 1959) and confirmed by the demonstration of oxygenated intermediates (Poole et al., 1979, 1983a) and extensive studies of the solubilized and purified complexes (reviewed by Poole, 1994). The cytochrome $b o^{\prime}$ quinol oxidase (the term $b o^{\prime}$ is used to describe the haem-O- and haem-B-containing quinol oxidase of $E$. coli, the superscript referring to the 
ligand-reactive haem in accordance with IUB nomenclature; Poole \& Chance, 1995) is regarded as a protonpumping oxidase, whereas cytochrome $b d$, which has a greater resistance to respiratory inhibitors, is not a proton pump and thereby is less effective at conserving the energy of respiratory electron transfer (Poole, 1983, 1994; Puustinen et al., 1991). Studies of the regulation of synthesis of the two oxidases reveal that cytochrome 'bo' is synthesized maximally under conditions of high oxygen availability, whereas cytochrome $b d$ is prominent under microaerobic conditions ( $\mathrm{Fu}$ et al., 1991), when the synthesis of cytochrome $b o^{\prime}$ is repressed (Cotter et al., 1990).

The oxygen affinities of both oxidases are widely cited in relation to this differential synthesis, even though most data have been obtained using techniques that are incapable of measuring high affinities (e.g. Kolonay et al., 1994). Rice \& Hempfling (1978), however, used a modified polarographic technique with a large volume chamber and a probe covered with an ultra-thin membrane to measure oxygen affinities of cells grown in an unusual ' phauxostat' device and obtained a $K_{\mathrm{m}}$ for oxygen of $24 \mathrm{nM}$ for cytochrome $b d$, in remarkable agreernent with the classical studies of Longmuir (1954). However, all studies involving polarographic methods are limited at low oxygen tensions by the 'unstirred layer' at the electrode membrane (Lundsgaard et al., 1978). Recognizing these limitations, we (D'mello et al., 1994a, 1995) recently modified a highly sensitive spectrophotometric means of continuously monitoring oxygen depletion, as reported by the deoxygenation of oxyleghaemoglobin or oxymyoglobin (Appleby \& Bergersen, 1980).

We report here the use of this method to demonstrate the exceptionally low $K_{\mathrm{m}}$ for oxygen for cytochrome $b d$ in $E$. coli using a strain defective in cytochrome $b o^{\prime}$. These measurements also reveal inhibition of oxidase activity at higher dissolved oxygen tensions, which may be important in regulating electron flux through branched respiratory chains in E. coli and other bacteria.

\section{METHODS}

Bacteria, growth, and preparation of cell and membrane suspensions. E. coli strain GL101 ( $\mathrm{F}^{-}$cyo $s d b C$; Lemieux $t$ al., 1992), which lacks the cytochrome $b o^{\prime}$ terminal oxidase, was a gift from Professor R. B. Gennis (University of Illinois, USA). Strain AN2342 ('wild-type'; Poole et al., 1989) was a gift from Professor F. Gibson (Australian National University). Both strains were grown in Luria-Bertani (LB) medium, $\mathrm{pH} 7 \cdot 0$ (Maniatis et al., 1982), supplemented with $0.2 \%(\mathrm{w} / \mathrm{v})$ glucose and, for strain GL101, kanamycin $\left(20 \mu \mathrm{g} \mathrm{ml}^{-1}\right)$ and tetracycline $\left(20 \mu \mathrm{g} \mathrm{m}^{-1}\right)$, in 21 baffled flasks containing $400 \mathrm{ml}$ medium at $37^{\circ} \mathrm{C}$ with shaking at 200 r.p.m. Cultures were grown to midexponential phase $(4 \mathrm{~h})$ or, for strain AN2342, to late-stationary phase $(20 \mathrm{~h})$. Cells were harvested by centrifugation at $4000 \mathrm{~g}$ for $10 \mathrm{~min}$; a portion (approximately $1 \mathrm{~g}$ ) of the cell paste was resuspended in $25 \mathrm{mM}$ potassium phosphate buffer $(5 \mathrm{ml})$ and retained at $4{ }^{\circ} \mathrm{C}$ until used (within $6 \mathrm{~h}$ ) for oxygen affinity determinations. The remaining cell paste was resuspended in $50 \mathrm{ml} 50 \mathrm{mM}$ PIPES buffer ( $\mathrm{pH} \mathrm{6.5)}$, containing $8 \mathrm{mM}$ magnesium acetate and a few grains of DNase (Sigma), and stored at $-70{ }^{\circ} \mathrm{C}$ for approximately $24 \mathrm{~h}$ until membrane vesicles were prepared using published procedures (D'mello et al., 1994a, 1995). In brief, the thawed cell suspension was passed through a French pressure cell (Aminco) at $69 \mathrm{MPa}$. Centrifugation at $27000 \mathrm{~g}$ for $15 \mathrm{~min}$ removed cell debris; membrane vesicles were recovered from the supernatant fraction by centrifugation at $100000 \mathrm{~g}$ for $90 \mathrm{~min}$. Membranes were suspended in the above buffer ( $4 \mathrm{ml}$, but lacking DNase) and stored at $4{ }^{\circ} \mathrm{C}$ until use (within $6 \mathrm{~h}$ ). Protein in cells and membranes was assayed by the method of Markwell et al. (1978).

Determination of oxygen affinities. This was carried out as described previously by D'mello et al. (1994a, 1995). Oxygenated soybean leghaemoglobin (courtesy of Dr F. J. Bergersen, CSIRO Division of Plant Industry, Canberra, Australia) or sperm whale myoglobin (Sigma, no longer available) was diluted to $10-15 \mu \mathrm{M}$ in phosphate buffer $(25 \mathrm{mM}, \mathrm{pH} 7 \cdot 0)$ containing $1 \mathrm{mM}$ EDTA, which had been previously sparged with, and stored under, a gas mixture of $1 \%(\mathrm{v} / \mathrm{v})$ oxygen in argon. Solutions were used within $6 \mathrm{~h}$. Deoxygenation of the globins by respiration of cells or membranes was monitored by time-shared multi-wavelength spectrophotometry (Chance et al., 1975) as described by D'mello et al. (1994a, 1995). The $1.3 \mathrm{ml}$ capacity cuvette was filled with the globin solution and sealed with a finely perforated stopper, through which substrate solution ( $1 \mathrm{M}$ succinate, $10 \mu \mathrm{l}$, or $1 \mathrm{M}$ D-lactate, $10 \mu \mathrm{l}$ ) was injected. The stability of the oxygenated globin was checked by monitoring $\Delta A$ for $5-10 \mathrm{~min}$. After addition of bacteria or membranes $(5-50 \mu \mathrm{l})$, globin deoxygenation was continuously monitored by plotting $\Delta A_{575-560}$. Data were analysed as described previously by D'mello et al. (1994a). At least four separate determinations were carried out on each sample; means and standard deviations are presented.

Low temperature spectrophotometry. The apparatus and techniques used to record photodissociation spectra of samples in the presence or absence of oxygen have been described previously (Poole et al., 1979). Suspensions of washed cells or membranes, containing $30 \%(\mathrm{v} / \mathrm{v})$ ethylene glycol, were reduced with sodium succinate $\left(5 \mathrm{mM}, 30 \mathrm{~min}, 30^{\circ} \mathrm{C}\right)$ or sodium lactate $\left(5 \mathrm{mM}, 30 \mathrm{~min}, 30^{\circ} \mathrm{C}\right)$ in a $2 \mathrm{~mm}$ pathlength cuvette ( $1 \mathrm{ml}$ capacity) and bubbled with $\mathrm{CO}$ for $2 \mathrm{~min}$ at room temperature. The cuvette was cooled to $-23^{\circ} \mathrm{C}$ and, when required, oxygen was introduced by vigorously stirring the contents with a coiled wire (20-30 vertical strokes), giving approximately $300 \mu \mathrm{M}$ oxygen in the sample, which was then rapidly frozen at $-78^{\circ} \mathrm{C}$ (dry ice/ethanol). After equilibration in the sample compartment of the spectrophotometer, a baseline was recorded (CO-reduced minus CO-reduced) and the sample was photolysed for 2 min with the focused beam from a $150 \mathrm{~W}$ lamp. Subsequent difference spectra (post-photolysis minus prephotolysis) reveal photodissociable haem proteins and their reactions with $\mathrm{CO}$ or oxygen.

\section{RESULTS}

\section{Spectral characteristics of the strains used}

The Cyo ${ }^{-}$phenotype of strain GL101 was confirmed by difference spectroscopy (results not shown). In the CO difference spectrum, an $\alpha$-band at $640 \mathrm{~nm}$ was identified as the CO-ligated form of cytochrome $d$ and a trough at $620 \mathrm{~nm}$ was assigned to loss of absorbance of the reduced, unligated cytochrome on binding CO. In the $\gamma$ (Soret)region, the absorption maximum was at $420 \mathrm{~nm}$ and the trough was at $442 \mathrm{~nm}$. These signals are quite distinct from those exhibited by cytochrome 0 in such spectra, namely a peak at $416 \mathrm{~nm}$ and a trough at $430 \mathrm{~nm}$ (Poole et 

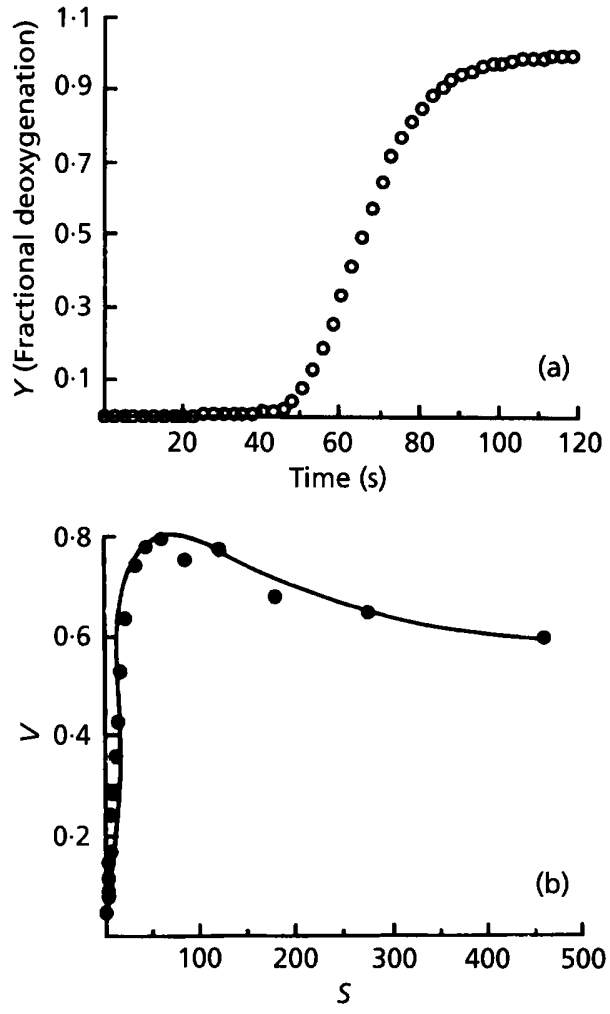

Fig. 1. Deoxygenation of oxyleghaemoglobin (a) during respiration of lactate by intact cells of E. coli GL101 (Cyo- Cyd ${ }^{+}$). Oxygen consumption rates $\left(V, \mathrm{nmol}^{-1}\right)$ and oxygen concentration $(S, n M)$ in (b) were derived as described previously by D'mello et al. (1994a).

al., 1979). The Soret band of cytochrome $d$ is weak (Poole et al., 1982a) and so the 420 and $442 \mathrm{~nm}$ bands do not arise from this component either. Therefore, we conclude that, as in Azotobacter vinelandii (D'mello et al., 1994b), these bands arise from $\mathrm{CO}$ binding to another haem in the cytochrome $b d$ complex, namely cytochrome $b_{595}$, and confirm that strain GL101 (Lemieux et al., 1992) contains cytochrome $b d$ as sole terminal oxidase and lacks cytochrome $b a^{\prime}$. The CO difference spectrum of the wild-type strain AN2342 (results not shown) grown to latestationary phase was similar to that of GL101, but the Soret region revealed a low concentration of cytochrome $o$, evident from a peak at $415 \mathrm{~nm}$, and a ' $\mathrm{W}$ '-shaped trough with minima at 430 and $443 \mathrm{~nm}$, attributable to cytochromes $o$ and $b_{595}$, respectively.

\section{Measurements of the oxygen affinity of the cytochrome-bd-type oxidase}

The basis and validity of the globin deoxygenation method have been described previously (D'mello et al., 1994a, 1995). Several precautions were taken. First, we demonstrated that absorbance at the selected wavelengths was unaffected by the presence of membranes or cells in the cuvette. Second, doubling the cell or membrane concentration did not affect the measured $K_{\mathrm{m}}$ values.
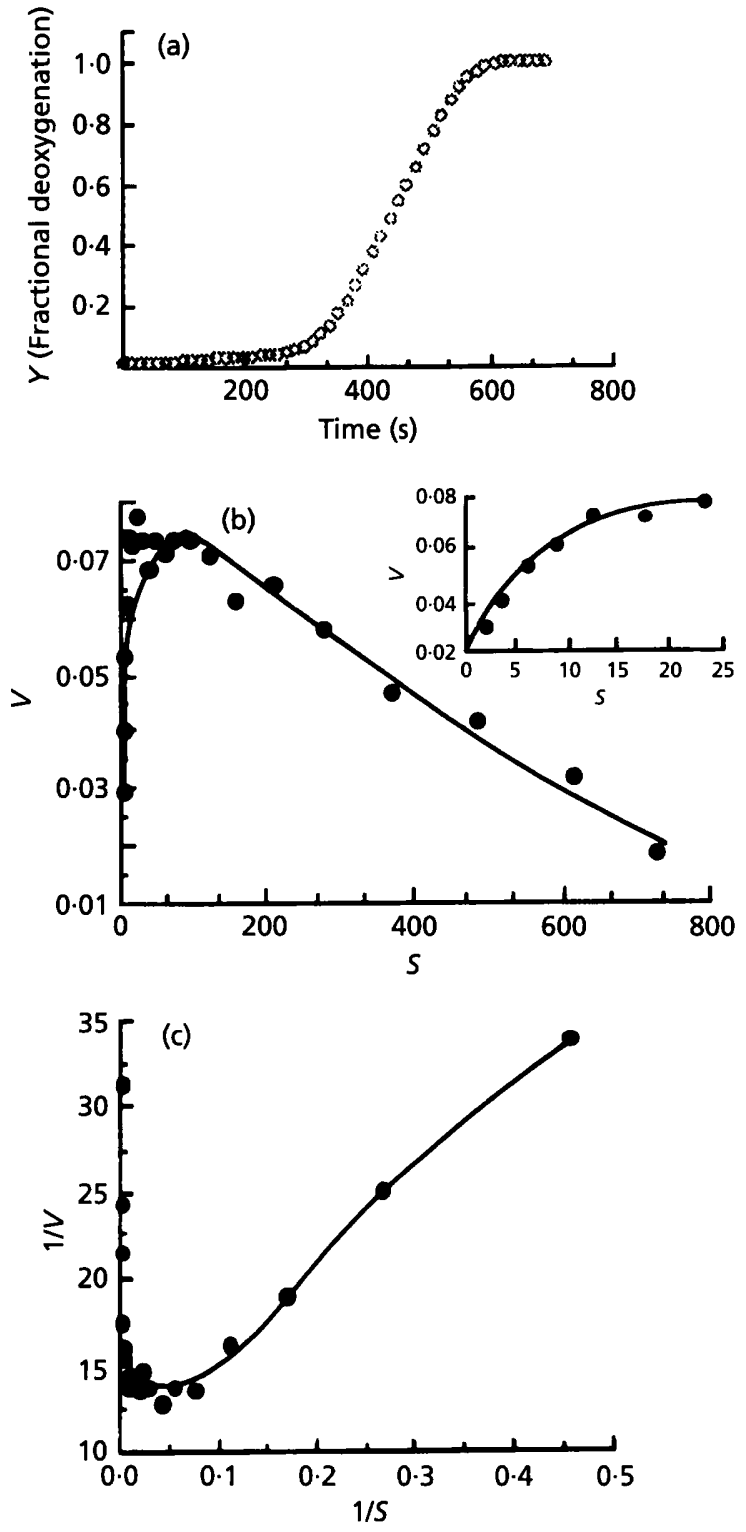

Fig. 2. Deoxygenation of oxyleghaemoglobin (a) during endogenous respiration of intact cells of $E$. coli GL101 (Cyo $\left.\mathrm{Cyd}^{+}\right)$. Oxygen consumption rates $\left(V, \mathrm{nmol} \mathrm{s}^{-1}\right)$ and oxygen concentration $(S, n M)$ in (b) and the inset were derived ( $D^{\prime}$ 'mello et al., 1994a) using the data obtained between 3 and $700 \mathrm{nM}$ oxygen [see part (a)], and the equations for substrate inhibition (Cleland, 1970). (c) Lineweaver-Burk plot.

Third, to ensure that the absorbance changes were attributable to deoxygenation, and not oxidation, of the globin, the cuvette contents were examined by wavelength-scanning before and after each deoxygenation experiment. In the calculation of results, full deoxygenation was taken as that level attained by respiration and not that achieved by dithionite; this avoids the problems caused by partial oxidation during the reaction or $\mathrm{Fe}(\mathrm{III})$ haem impurities in the globin sample used. Only data that were within the working range of each globin (D'mello et al., 1994a) were examined. 
Table 1. Oxygen affinities of cytochrome bd in $E$. coli cells and membranes

E. coli AN2342 is a wild-type strain and was grown to late-stationary phase to minimize the contribution of cytochrome $b o^{\prime}$ and maximize cytochrome $b d$ (see text). GL101 is $\mathrm{Cyo}^{-}$. The values presented are means of four to six determinations with standard deviations in parentheses. The $K_{m}$ values were calculated from the equations of Cleland (1970). ND, No component detected; -, not done.

\begin{tabular}{|c|c|c|c|c|c|}
\hline \multirow[t]{2}{*}{ Strain } & \multirow{2}{*}{$\begin{array}{l}\text { Preparation, } \\
\text { substrate }\end{array}$} & \multirow{2}{*}{$\frac{\text { Myoglobin }}{K_{\mathrm{m}}(\boldsymbol{\mu M})}$} & \multicolumn{3}{|c|}{ Leghaemoglobin } \\
\hline & & & $K_{\mathrm{m}}(\mathrm{nM})$ & $K_{\mathrm{i}}(\mu \mathrm{M})$ & $V_{\max }\left[\mathrm{nmol} \mathrm{s}^{-1}(\mathrm{mg} \text { protein })^{-1}\right]$ \\
\hline AN2342 & Membranes, succinate & ND & $3 \cdot 4(1 \cdot 4)$ & $0.94(0 \cdot 23)$ & $0.49(0.21)$ \\
\hline \multirow[t]{3}{*}{ GL101 } & Cells, lactate & - & $8 \cdot 4(2 \cdot 1)$ & $0.83(0.12)$ & $1 \cdot 13(0 \cdot 17)$ \\
\hline & Cells, endogenous & ND & $3 \cdot 0(2 \cdot 7)$ & $0.54(0.07)$ & $0.055(0.001)$ \\
\hline & Membranes, lactate & - & $5 \cdot 8(0 \cdot 6)$ & $1 \cdot 81(0 \cdot 47)$ & $2.05(0.39)$ \\
\hline
\end{tabular}

The deoxygenation kinetics of oxymyoglobin and oxyleghaemoglobin were followed with both cells and membrane preparations from strain GL101. Data for intact cells respiring lactate (GL101 being defective in succinate dehydrogenase) are shown in Fig. 1(a, b). The progress of deoxygenation of oxyleghaemoglobin (Fig. 1a) was used to compute the plot (Fig. 1b) of oxygen consumption rate $(V)$ versus oxygen concentration $(S)$. Respiration rates increased to a maximum at approximately $50 \mathrm{nM}$ oxygen and declined at higher oxygen concentrations. Similar results were obtained with membranes (not shown). The most striking example of the decline in respiration at higher oxygen concentrations was afforded by experiments with whole cells respiring endogenous substrates (Fig. 2). The $V$ versus $S$ plot (Fig. 2b), calculated from the deoxygenation kinetics (Fig. 2a), showed that respiration rate increased sharply with increasing oxygen concentration. The inset in Fig. 2(b) shows an expanded abscissa and reveals more clearly the increasing respiration rate at oxygen concentrations up to about $25 \mathrm{nM}$. At oxygen concentrations above $25 \mathrm{nM}$, respiration decreased linearly as dissolved oxygen concentration increased. The Lineweaver-Burk plot (Fig. 2c) showed behaviour typical of substrate inhibition. Analyses using the equations of Cleland (1970) of several similar experiments using oxyleghaemoglobin as supplier and monitor of dissolved oxygen are summarized in Table 1 . The $K_{\mathrm{m}}$ values obtained with whole cells and membranes, using either lactate or endogenous substrates, were in the range 3-8.4 nM, markedly lower than any previously determined value. The $K_{\mathrm{i}}$ values obtained were in the range $0.54-1.81 \mu \mathrm{M}$ for strain GL101. The highest affinity was observed in cells respiring slowly $\left[V_{\max }=0.055 \mathrm{nmol}\right.$ oxygen $\mathrm{s}^{-1}$ (mg protein) ${ }^{-1}$.

To determine whether the kinetics observed could be demonstrated in the wild-type strain, E. coli strain AN2342 was grown to late-stationary phase to minimize the contribution of cytochrome $b o^{\prime}$ and maximize that of cytochrome $b d$. Membranes from this strain, oxidizing succinate, gave a $K_{\mathrm{m}}$ for oxygen of about $3 \mathrm{nM}$ (Table 1) and also exhibited substrate inhibition $\left(K_{\mathrm{i}}=0.94 \mu \mathrm{M}\right)$.

These experiments exploited the low dissociation constant of oxyleghaemoglobin to measure oxygen consumption kinetics in the range $0.003-0.3 \mu \mathrm{M}$ (Bergersen \& Turner,
1985). To check for the presence of a component in these strains with an oxygen affinity in the $0 \cdot 3-10 \mu \mathrm{M}$ range, oxymyoglobin was also used (Table 1). No component could be detected, consistent with the absence of cytochrome $b o^{\prime}$ in strain GL101 and the low levels of this oxidase in strain AN2342 grown under these conditions. We have previously shown that oxymyoglobin can be used to determine oxygen affinities for cytochrome $b o^{\prime}$ of E. coli (D'mello et al., 1995) and A. vinelandii cytochrome bd (D'mello et al., 1994a).

\section{Ligand-binding reactions of cytochrome bd}

The classical interpretation of substrate inhibition kinetics is that, at high (generally non-physiological) concentrations, the substrate acts as an inhibitor by binding to a second site in the enzyme, generating a 'dead-end' complex (Cleland, 1970). To date, evidence has not been presented that the $E$. coli cytochrome $b d$ binds oxygen at two sites. However, this would be consistent with the proposal that $\mathrm{CO}$ and nitrite bind to both cytochrome $d$ and cytochrome $b_{595}$ (Hill et al., 1993; Rothery et al., 1987), that cyanide exhibits concerted binding to these haems - perhaps as a bridging ligand (Krasnoselskaya et $a l ., 1993)$, and that cytochrome $b_{595}$ binds CO in a lightreversible manner (Poole \& Chance, 1981). Furthermore, the $A$. vinelandii cytochrome $b d$ binds both $C O$ and oxygen at each high-spin haem (D'mello et al., 1994b).

To extend these studies, photodissociation spectra of strain GL101, lacking cytochrome $b o^{\prime}$, were recorded. Fig. 3 shows the photolysed (i.e. reduced, unligated) minus pre-photolysis (i.e. reduced, CO-ligated) difference spectrum recorded in the absence of oxygen at $-100^{\circ} \mathrm{C}$. Although conventional $\mathrm{CO}$ difference spectra of this strain are dominated by the $\mathrm{CO}$-ligated and reduced forms of cytochromes $d$ and $b_{595}$, the characteristic features of cytochrome $d$ in the 630-680 $\mathrm{nm}$ region are not detectable in this spectrum or after photolysis at other temperatures between -60 and $-130^{\circ} \mathrm{C}$ in the absence of oxygen (results not shown). This behaviour has been reported previously (Poole et al., 1982a) and is the result of rapid rebinding of $\mathrm{CO}$ to cytochrome $d$ after photolysis. Peaks in Fig. 3 at 439, 555 and $592 \mathrm{~nm}$ are attributed to the unligated $\mathrm{Fe}(\mathrm{II})$ form of haemoprotein(s); troughs at 421, about 532 , and $570 \mathrm{~nm}$ result from loss of the CO-ligated 


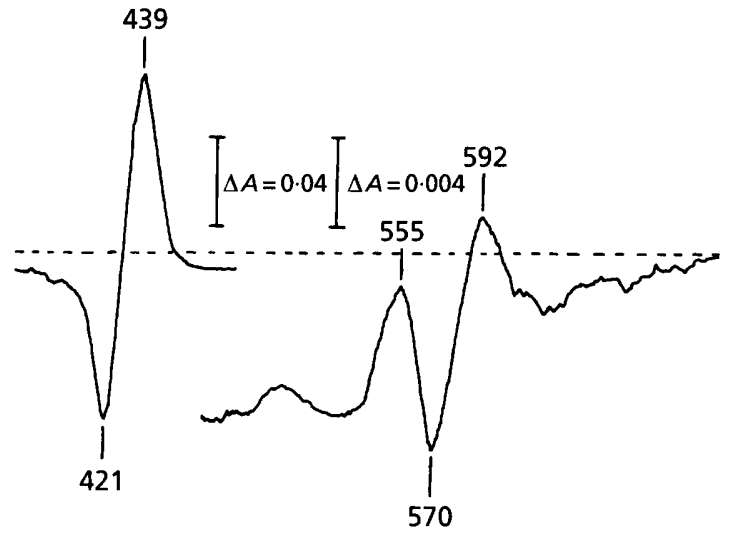

Fig. 3. Photodissociation spectrum of lactate-reduced, COligated whole cells of $E$. coli GL101 $\left(\mathrm{Cyo}^{-} \mathrm{Cyd}^{+}\right)$in the absence of oxygen at $-130^{\circ} \mathrm{C}$. The spectrum was recorded immediately after photolysis in the dual-wavelength scanning mode, with $575 \mathrm{~nm}$ as the reference wavelength, at $2.86 \mathrm{~nm} \mathrm{~s}^{-1}$ and a spectral band width of $4 \mathrm{~nm}$. The pre-photolysis reduced plus $\mathrm{CO}$ minus reduced plus $\mathrm{CO}$ baseline is shown as a dashed line.

form. The signals are characteristic of a high-spin haemB-containing protein, the spectrum resembling, for example, the (inverted) $\mathrm{CO}$ difference spectrum of myoglobin (Wood, 1984). The Soret: $\alpha / \beta$ ratio [ $\Delta A_{439-421} / \Delta A_{555-570}$, as defined by Wood (1984)] is high, being 21 at $-100^{\circ} \mathrm{C}$ (Fig. 3) and 28 at $-130^{\circ} \mathrm{C}$ (not shown). However, these are minimum values, since the sample dilutions used, to maximize the resolution of the $\alpha$ and $\beta$ bands, were not optimal for avoiding suppression of the Soret bands (i.e. those regions of the spectrum where light scattering is most severe). Typical Soret: $\alpha / \beta$ ratio values for high-spin haem $B$ proteins are around 32 . Since strain GL101 does not express cytochrome $b o^{\prime}$, and because cytochrome $d$ is not detected under these conditions, the band at $592-595 \mathrm{~nm}$ is assigned to reduced, unligated cytochrome $b_{\mathbf{5 9 5}}$, as is the $439 \mathrm{~nm}$ band (D'mello et al., 1994a; Rothery et al., 1987). We anticipated that maximal amplitude of the Soret signals of cytochrome $b_{595}$ (439 $\mathrm{nm}$ peak, $421 \mathrm{~nm}$ trough) immediately after photolysis would be observed at the lowest temperatures, because the lowest recombination rates are expected at these temperatures. However, the amplitude was maximal at $-80^{\circ} \mathrm{C}$, being higher than the amplitudes at $-100^{\circ} \mathrm{C}$ and $-130^{\circ} \mathrm{C}$ (results not shown). This might be the consequence of geminate recombination (Gibson, 1989) at the lower temperatures, i.e. the rapid return of a ligand molecule to the same site from which it has been photolysed.

The $439 \mathrm{~nm}$ peak and $421 \mathrm{~nm}$ trough decreased in amplitude after photolysis, approaching the baseline without change in band shape or position, indicating recombination of the cytochrome with $\mathrm{CO}$. This is illustrated for $-60^{\circ} \mathrm{C}$ in Fig. 4(a). The kinetics were pseudo-first order (Fig. 4c), with a half-time at $-60^{\circ} \mathrm{C}$ of $>50 \mathrm{~min}$. These changes were fully reversible by re-photolysis of the sample. At $-100^{\circ} \mathrm{C}$, negligible $(<\approx 4 \%$ ) recombination was observed over a $60 \mathrm{~min}$ observation time (Fig. 4c).

To determine whether cytochrome $b_{595}$ binds oxygen, photodissociation spectra were recorded after introducing
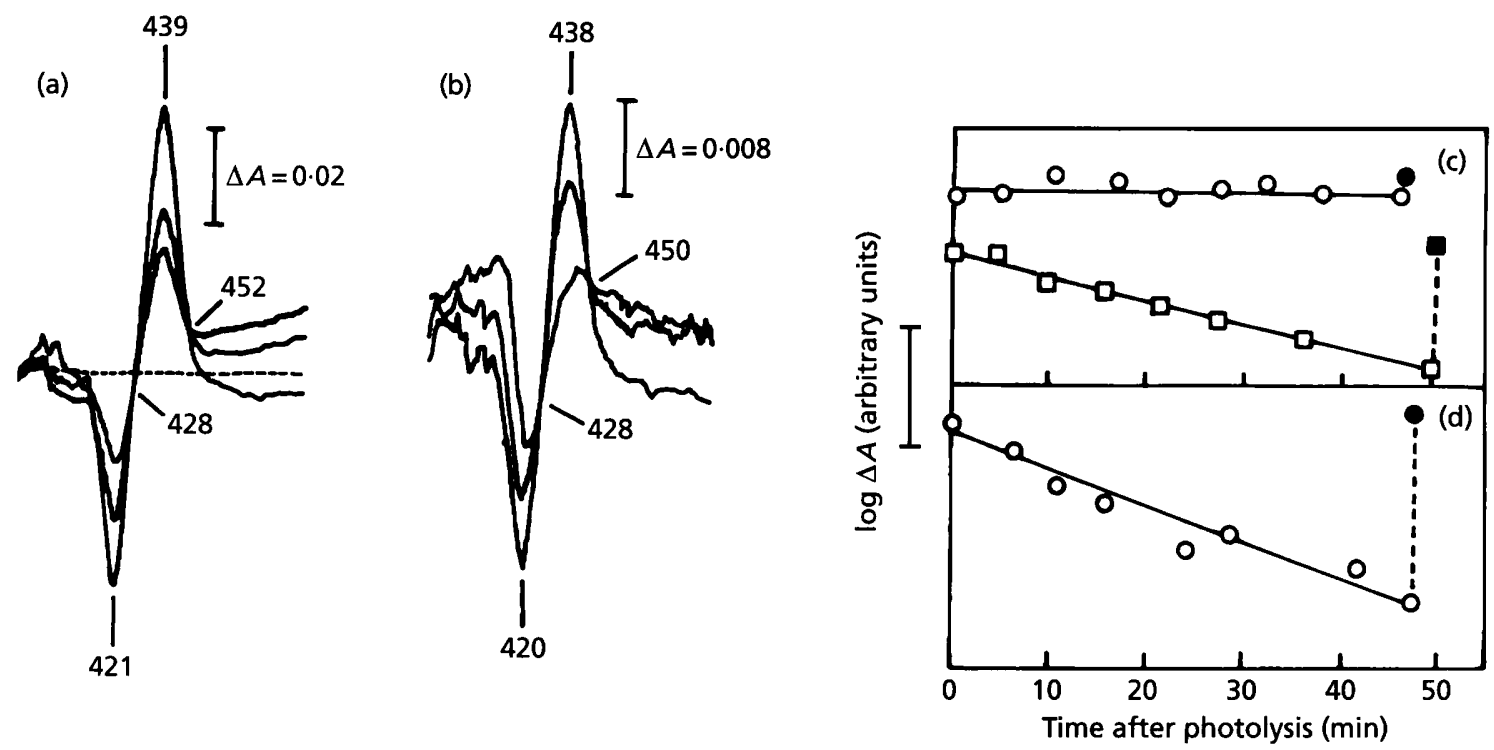

Fig. 4. Kinetics of the reactions of oxygen and $\mathrm{CO}$ with cytochrome $b_{595}$ in $E$. coli GL101 (Cyo- Cyd ${ }^{+}$). (a) Spectra recorded after photolysis of the lactate-reduced, CO-ligated sample in the absence of oxygen at $-60^{\circ} \mathrm{C}$. Scans were recorded at 0 , 28 and $62 \mathrm{~min}$ after photolysis and approach the baseline (dashed). (b) Spectra recorded after photolysis in the presence of oxygen at $-100^{\circ} \mathrm{C}$ at 0,11 and $47.5 \mathrm{~min}$. Absorbance changes $(439-475 \mathrm{~nm})$ in the absence of oxygen at $-100{ }^{\circ} \mathrm{C}(O)$ or $-60^{\circ} \mathrm{C}[\square$, from part (a)] are shown in (c); closed symbols show $\Delta A$ after re-photolysis at the time indicated. (d) $A$ similar plot for spectra obtained in the presence of oxygen at $-100^{\circ} \mathrm{C}$ [see part (b)]. The bar in (c) and (d) shows a twofold change in $\Delta A$. 

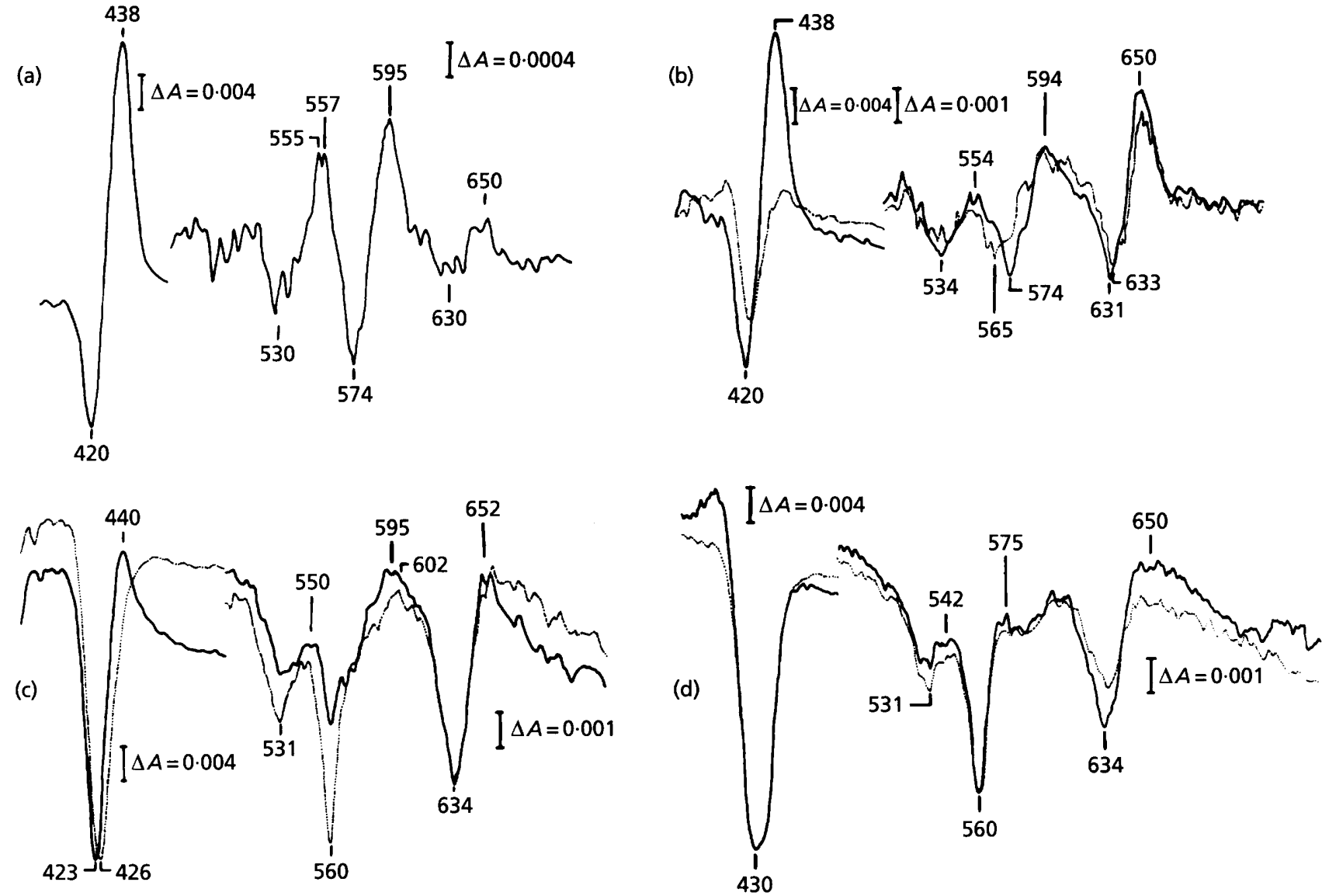

Fig. 5. Photodissociation spectra of lactate-reduced, CO-ligated whole cells of $E$. coli GL101 (Cyo- Cyd ${ }^{+}$) supplemented with oxygen at $-130^{\circ} \mathrm{C}(\mathrm{a}),-100^{\circ} \mathrm{C}(\mathrm{b}),-80^{\circ} \mathrm{C}(\mathrm{c})$ and $-60^{\circ} \mathrm{C}(\mathrm{d})$. The solid lines are the spectra recorded immediately after photolysis and the dotted lines in (b-d) are spectra recorded approximately $1 \mathrm{~h}$ after photolysis. Spectra were recorded in the dual-wavelength scanning mode, with $575 \mathrm{~nm}$ as the reference wavelength, at $2.86 \mathrm{~nm} \mathrm{~s}^{-1}$ and a spectral band width of $4 \mathrm{~nm}$. Pre-photolysis reduced plus $\mathrm{CO}$ minus reduced plus CO baselines (not shown) were featureless.

oxygen at $-23^{\circ} \mathrm{C}$ immediately before freeze-trapping. At $-130^{\circ} \mathrm{C}$ (Fig. 5a), the dominant peaks were at 595 , $555-557$ and $438 \mathrm{~nm}$, very similar to those observed in the absence of oxygen (Fig. 3) and therefore attributable to cytochrome $b_{595}$. However, a new signal at $650 \mathrm{~nm}$ was observed, due to oxygenated cytochrome $d$ (Poole $t$ t al., 1983a). This signal was most intense at $-100^{\circ} \mathrm{C}$ (Fig. $5 \mathrm{~b}$ ). At $-80{ }^{\circ} \mathrm{C}$ (Fig. 5c) and $-60^{\circ} \mathrm{C}$ (Fig. 5d), spectra recorded at frequent intervals after photolysis (not shown) showed development of a trough at $560 \mathrm{~nm}$, due to cytochrome $b$ oxidation and the approach of the $438 \mathrm{~nm}$ peak to the baseline. These photodissociation spectra are similar to those described previously in which a $632.8 \mathrm{~nm}$ He-Ne laser was used to photolyse selectively the cytochrome $d-\mathrm{CO}$ complex (Poole et al., 1983b; Poole \& Williams, 1987). In both that work and in the present, the first scan after photolysis at $-100{ }^{\circ} \mathrm{C}$ reveals the characteristic signals of cytochrome $d$ between 631 and $650 \mathrm{~nm}$. Cytochrome $b_{595}$ is more prominent, relative to the cytochrome $d$ signal, after photolysis with 'white' light (Fig. 5b) than after photolysis with the laser (Poole \& Williams, 1987). This is expected, since the CO-ligated form of cytochrome $d$ (with absorbance maximum near
$636 \mathrm{~nm}$ ) more effectively absorbs the photolysing radiation $(632.8 \mathrm{~nm})$ than does the CO-ligated form of cytochrome $b_{595}$ (with absorbance maximum near $570 \mathrm{~nm}$ ). Following photolysis with the laser, oxidation of cytochrome $b_{595}$ was observed to accompany disappearance of oxy-cytochrome $d$ (Poole \& Williams, 1987). Further studies of the reaction progress following photolysis with white light will be necessary to understand the electron transfer events under these conditions.

Fig. 4(b) shows repetitive scanning of the reaction progress with oxygen at $-100^{\circ} \mathrm{C}$; both the $438 \mathrm{~nm}$ peak and the $420 \mathrm{~nm}$ trough approached the baseline, without initial detectable shift in band positions and at a greater rate than in anoxic samples. Since the baseline is the spectrum of the reduced, CO-ligated sample, the spectral changes indicate the binding of a ligand (oxygen) to cytochrome $b_{595}$ to give an adduct with spectral properties similar to those of the CO-ligated species. The kinetics were pseudo-first order (Fig. $4 \mathrm{~d}$ ), with a $t_{1 / 2}$ at $-100{ }^{\circ} \mathrm{C}$ of about $35 \mathrm{~min}$. The rate of ligand binding to cytochrome $b_{595}$ was thus much greater in the presence of oxygen. Indeed, in the absence of oxygen, no measurable ligand 
binding occurred after photolysis of the CO compound until the temperature was raised to about $-60^{\circ} \mathrm{C}$ (this work) or higher (Poole et al., 1981). Interestingly, we noted that, even in the presence of oxygen, the absorbance changes in the Soret region attributed to cytochrome $b_{595}$ were fully reversible by white light (Fig. 4d).

\section{DISCUSSION}

The deoxygenation of oxyleghaemoglobin provides a suitably sensitive assay for the determination of the oxygen affinity of cytochrome $b d$. The $K_{\mathrm{m}}(3-8 \mathrm{nM})$ determined by this method is about fourfold lower than that measured with a modified oxygen electrode with growing cells (Rice \& Hempfling, 1978). Much higher values have been obtained using conventional Clark-type oxygen electrodes and cytochrome $b d$ purified from $E$. coli. Kita et al. (1984) obtained a value of $0.38 \mu \mathrm{M}$ using an electrode 'sensitive to low oxygen concentration', whilst Kolonay et al. (1994) drew 'tangents to the oxygen consumption curves at intervals of $0.5 \mu \mathrm{M}$, resulting in approximately 20 separate rates' and reported a $K_{\mathrm{m}}$ value of $2 \mu \mathrm{M}$, almost 1000 -fold higher than the lowest values given in the present paper. The purified cytochrome-bdtype oxidase from Klebsiella pneumoniae has also been shown to have a very high affinity for oxygen $\left(K_{\mathrm{m}} 20 \mathrm{nM}\right)$, measured using the spectral properties of leghaemoglobin (Smith et al., 1990). The astonishingly high apparent affinity for oxygen of the $E$. coli cytochrome $b d$ is in marked contrast to cytochrome $b d$ in $A$. vinelandii, which has an apparent $K_{\mathrm{m}}$ for oxygen of about $4.5 \mu \mathrm{M}$ (D'mello et al., 1994a), measured using the same method. All three oxidases are structurally very similar and the disparity in the measured $K_{\mathrm{m}}$ values is surprising. It should be noted, however, that our values for $A$. vinelandii (D'mello et al., 1994a) and E. coli (this paper) were determined in situ using either membranes or cells and the direct electron donor to the oxidase in these experiments is therefore the natural quinone pool. In contrast, the value for the $K$. pneumoniae oxidase, for example, was determined for the purified oxidase provided with ubiquinol-1, duroquinol or $N, N, N^{\prime}, N^{\prime}$-tetramethyl- $p$-phenylenediamine as substrates, and DTT or ascorbate to maintain the donors in their reduced states. It is probable that the nature and concentration of electron donor used in these various experiments is in part responsible for the disparate $K_{\mathrm{m}}$ values reported.

The physiological function of the $A$. vinelandii oxidase is rapid oxygen consumption and respiratory protection of nitrogenase (Kelly et al., 1990; Poole, 1994) and the K. pneumoniae oxidase has also been proposed to lower the oxygen concentration and allow nitrogenase synthesis and function (Smith et al., 1990). Similar roles for cytochrome $b d$ in E. coli have been demonstrated (Hill et al., 1990): mutants of $E$. coli defective in cytochrome bd show increased sensitivity to oxygen of fermentation and of microaerobic oxygen-dependent nitrogenase activity in vivo (in strains harbouring $K$. pneumoniae nif genes). The very high affinity of the E. coli oxidase reported here is consistent with the view that this oxidase serves to scavenge oxygen under oxygen-limited growth conditions.

Oxygen concentrations higher than about $50 \mathrm{nM}$ inhibit respiration via cytochrome $b d$. Substrate inhibition is particularly marked under conditions of low electron flux through the oxidase. These results have interesting physiological implications for the control of respiratory electron flux in $E$. coli and provide a possible solution to an enigma. Studies using $c y d A B-l a c Z$ fusions have shown that cytochrome $b d$ expression is not shut down during aerobic growth (Cotter et al., 1990). Cytochrome bo' levels increase about 150 -fold over anaerobic conditions, but cytochrome $b d$ levels fall only 3 -fold from 600 molecules per cell during anaerobic growth. We propose that inhibition of cytochrome $b d$ activity at intracellular oxygen concentrations in the micromolar range might achieve appropriate control of electron flux through the proton pumping branch, i.e. that terminated by cytochrome $b o^{\prime}$, rather than through the non-proton pumping cytochrome bd (Puustinen et al., 1991). Rothery et al. (1987) also noted a slight increase in respiration rate as oxygen concentration fell from about $180 \mu \mathrm{M}$ to $60 \mu \mathrm{M}$, but did not attribute this to oxidase activity. Such a model for control of respiratory flux is applicable in principle to any branched respiratory system in which one oxidase is of the $b d$ type, and might be extended to other branched chains for which models implicating the redox poise of the quinol pool (Guerin \& Camougrand, 1994) are currently considered. Oxygen inhibition of respiration also occurs in cysts and trophozoites of the parasitic protozoon Giardia muris (Paget et al., 1989), but in this case inhibition of the (unidentified) oxidase occurs at oxygen concentrations greater than $15-27 \mu \mathrm{M}$ and is irreversible.

There has been much uncertainty regarding the number of ligand-reactive haems in cytochrome $b d$ of $E$. coli. The evidence that cytochrome $d$ binds both $\mathrm{CO}$ and oxygen is unequivocal; in addition to the photochemical action spectrum (Castor \& Chance, 1959), evidence for oxygen binding has come from photolysis of CO-ligated cytochrome $d$ in the presence of oxygen at low temperatures, resulting in the oxygenated form (Poole et al., 1983a), and resonance Raman spectroscopy (Poole et al., 1982b; Kahlow et al., 1991). The early photochemical action spectra of stationary phase cells (Castor \& Chance, 1959) did not reveal a band that could be attributed to the second high-spin haem of the complex (cytochrome $b_{595}$, then called $a_{1}$ ) in the $\alpha$-region. However, subsequent photochemical action spectra using a liquid dye laser as actinic light source (Edwards et al., 1981) revealed in $E$. coli (and $A$. vinelandii) a very clear band at $592 \mathrm{~nm}$, which was attributed to 'cytochrome $a_{1}$ '. These measurements were not extended to $>610 \mathrm{~nm}$ (because of the range of the dye used) and therefore did not reveal the anticipated band of cytochrome $d$. Nevertheless, in the belief that cytochrome $b_{595}$ is not an oxidase in E. coli, these results have remained puzzling, unsubstantiated and largely ignored.

The present photodissociation spectra obtained with a $\mathrm{CyO}^{-}$strain confirm the CO-binding behaviour of cyto- 
chrome $b_{595}$ in E. coli and demonstrate for the first time oxygen binding by this haem. The spectral features of the $E$. coli cytochrome- $b d$-type oxidase are indistinguishable from those described recently for $A$. vinelandii (D'mello $e t$ al., 1994b). The clarity of the signals obtained in the cytochrome $b o^{\prime}$-deficient mutant must lead us to question our previous assignment of a $436 \mathrm{~nm}$ peak in lowtemperature photodissociation spectra to a form of cytochrome $o$ (Poole \& Chance, 1981); it seems likely that this component was cytochrome $b_{595}$. Comparison of the kinetics of ligand recombination after photolysis in the absence or presence of oxygen, as measured in the Soret region, strongly supports the view that cytochrome $b_{595}$ binds oxygen and provides a molecular basis for the substrate inhibition phenomenon. We cannot rule out the possibility that oxygen binding to cytochrome $d$ dramatically increases the rate of CO binding to cytochrome $b_{595}$ (positive co-operativity). However, the view that cytochrome $b_{595}$ binds oxygen is consistent with (i) the photochemical action spectrum of Edwards et al. (1981), (ii) the emerging view that the active site of this oxidase is a haem-haem 'binuclear' centre (D'mello et al., 1994b; Hill et al., 1993; Krasnoselskaya et al., 1993) functionally analogous to haem- $\mathrm{Cu}_{\mathrm{B}}$, and (iii) the present measurements of oxygen uptake kinetics, which implicate a second site for oxygen binding. The present data do not allow us to identify the haem that binds oxygen at the lowest concentrations of oxygen. It is noteworthy, however, that the formation of oxy-cytochrome $d$ is less extensive at the lowest temperatures used for photolysis, suggesting sluggish reactivity with the ligand under such conditions. Although little is known about the ligand reactivities of haems $b_{595}$ and $d$, we note that the haem of cytochrome $d$ is a chlorin, i.e. a porphyrin in which one ring ( $\mathrm{C}$ in haem $D)$ is reduced by saturation of one $\beta$-pyrrolic double bond (Timkovitch et al., 1985). Another chlorin-type structure is sulfhaemoglobin, in which $\mathrm{H}_{2} \mathrm{~S}$ adds across a $\beta-\beta$ double bond of a pyrrole, disrupting the porphyrin conjugation and forming a chlorin (Berzofsky et al., 1971). Sulfhaemoglobin is one of the main non-functional forms of haemoglobin and, by extension, it might be supposed that oxygen co-ordination by cytochrome $d$ will be sluggish. However, nitrite reacts with cytochrome $b_{595}$ about 10 fold slower than with cytochrome $d$ (Rothery et al., 1987).

Proposals regarding co-operativity between two oxygenbinding sites in bacterial oxidases have been made before. Kinetics of oxygen reduction by Pseudomonas aeruginosa cytochrome $c d_{1}$ (a nitrite reductase that also reduces oxygen; Poole, 1983) led Ingledew \& Saraste (1979) to conclude that this complex, containing two cytochromes $c$ and two cytochromes $d_{1}$, can reduce oxygen to water in two ways. In the first, at high oxygen, the enzyme has a high apparent $K_{\mathrm{m}}$ and $V_{\max }$. Oxygen is bound to each $d_{1}$ haem. At low oxygen concentrations, only a single oxygen is bound and is fully reduced to water. Migration of $\mathrm{O}_{2}^{2-}$ from one haem to the second may be necessary for full reduction. Based on the kinetics of inhibition by nitrite of cytochrome $b d$ in E. coli membranes, Rothery et al. (1987) hypothesized the existence of two oxygen-binding sites in this oxidase. Whether the presence of two sites might explain the ability to relieve $\mathrm{CO}$ inhibition of respiration by photolysis of either the $\mathrm{CO}$-cytochrome $d$ adduct (Castor \& Chance, 1959) or the CO-cytochrome $b_{595}$ adduct (Edwards et al., 1981) can be answered only by further study.

\section{ACKNOWLEDGEMENTS}

This work was supported by SERC (BBSRC) through a CASE Studentship (R.D.M.) and a research grant (R.K.P.), by an AFRC (BBSRC) Linked Research Grant (S. H., R. K.P.), and the Royal Society through equipment grants and a Leverhulme Trust Senior Research Fellowship (R.K.P.). We also thank Dr C. A. Appleby for stimulating discussion, Dr F. J. Bergersen for gifts of globins and helpful advice, Dr P. Butterworth for assistance with kinetic analyses, and Dr J. Peisach for bringing to our attention the properties of chlorin haems.

\section{REFERENCES}

Appleby, C. A. \& Bergersen, F. J. (1980). Methods of Evaluating Biological Nitrogen Fixation, pp. 315-335. Edited by F. J. Bergersen. Chichester: John Wiley.

Bergersen, F. J. \& Turner, G. L. (1985). Measurements of components of proton motive force and related parameters in steady state, microaerobic conditions. J Microbiol Methods 4, 13-23.

Berzofsky, J. A., Peisach, J. \& Blumberg, W. E. (1971). Sulphaem proteins. 1. Optical and magnetic properties of sulfmyoglobin and its derivatives. J Biol Chem 246, 3367-3377.

Castor, L. N. \& Chance, B. (1959). Photochemical determinations of the oxidases of bacteria. $J$ Biol Chem 234, 1587-1592.

Chance, B., Legallais, V., Sorge, J. \& Graham, N. (1975). A versatile time-sharing multichannel spectrophotometer, reflectometer and fluorometer. Anal Biocbem 66, 498-514.

Cleland, W. W. (1970). The Enzymes, vol. 2, pp. 1-65. Edited by P. D. Boyer. New York: Academic Press.

Cotter, P. A., Chepuri, V., Gennis, R. B. \& Gunsalus, R. P. (1990). Cytochrome $o$ (cyo $A B C D E)$ and $d(c y d A B)$ oxidase gene expression in Escherichia coli is regulated by oxygen, $\mathrm{pH}$ and the for gene product. J Bacteriol 172, 6333-6338.

D'mello, R., Hill, S. \& Poole, R. K. (1994a). Determination of the oxygen affinities of terminal oxidases in Azotobacter vinelandii using the deoxygenation of oxyleghaemoglobin and oxymyoglobin: cytochrome $b d$ is a low-affinity oxidase. Microbiology 140, 1395-1402.

D'mello, R., Palmer, S., Hill, S. \& Poole, R. K. (1994b). The cytochrome bd terminal oxidase of Azotobacter vinelandii: low temperature photodissociation spectrophotometry reveals reactivity of cytochromes $b_{595}$ and $d$ with both carbon monoxide and oxygen. FEMS Microbiol Lett 121, 115-120.

D'mello, R., Hill, S. \& Poole, R. K. (1995). The oxygen affinity of cytochrome bo' in Escherichia coli determined by the deoxygenation of oxyleghaemoglobin and oxymyoglobin: $K_{\mathrm{m}}$ values for oxygen are in the submicromolar range. J Bacteriol 177, 867-870.

Edwards, C., Beer, S., Siviram, A. \& Chance, B. (1981). Photochemical action spectra of bacterial $a$ - and 0 -type oxidases using a dye laser. FEBS Lett 128, 205-207.

Fu, H.-A., luchi, S. \& Lin, E. C. C. (1991). The requirement of ArcA and Fnr for peak expression of the cyd operon in Escherichia coli under microaerobic conditions. Mol E Gen Genet 226, 209-213.

Gibson, Q. H. (1989). Hemoproteins, ligands and quanta. $J$ Biol Chem 264, 20155-20158. 
Guerin, M. G. \& Camougrand, N. M. (1994). Partitioning of electron flux between the respiratory chains of the yeast Candida parapsilosis: parallel working of the two chains. Biochim Biophys Acta 1184, 111-117.

Hill, J. J., Alben, J. O. \& Gennis, R. B. (1993). Spectroscopic evidence for a haem-haem binuclear center in the cytochrome $b d$ ubiquinol oxidase from Escherichia coli. Proc Natl Acad Sci US A 90, 5863-5867.

Hill, S., Viollet, S., Smith, A. T. \& Anthony, C. (1990). Roles for enteric $d$-type cytochrome oxidase in $\mathrm{N}_{2}$ fixation and microaerobiosis. J Bacteriol 172, 2071-2078.

Ingledew, W. J. \& Saraste, M. (1979). The reaction of cytochrome $c d_{1}$ with oxygen and peroxides. Biochem Soc Trans 7, 166-168.

Kahlow, M. A., Zuberi, T. M., Gennis, R. B. \& Loehr, T. M. (1991). Identification of a ferryl intermediate of Escherichia coli cytochrome $d$ terminal oxidase by resonance Raman spectroscopy. Biochemistry 30, 11485-11489.

Kelly, M. J. S., Poole, R. K., Yates, M. G. \& Kennedy, C. (1990). Cloning and mutagenesis of genes encoding the cytochrome $b d$ terminal oxidase complex in Azotobacter vinelandii: mutants deficient in the cytochrome $d$ complex are unable to fix nitrogen in air. $J$ Bacteriol 172, 6010-6019.

Kita, K., Konishi, K. \& Anraku, Y. (1984). Terminal oxidases of Escherichia coli aerobic respiratory chain. II. Purification and properties of cytochrome $b_{558}-d$ complex from cells grown with limited oxygen and evidence of branched electron-carrying systems. $J$ Biol Chem 259, 3375-3381.

Kitts, C. L. \& Ludwig, R. A. (1994). Azorbizobium caulinodans respires with at least four terminal oxidases. J Bacteriol 176, 886-895.

Kolonay, J. F., Moshiri, F., Gennis, R. B., Kaysser, T. M. \& Maier, R. J. (1994). Purification and characterization of the cytochrome $b d$ complex from Azotobacter vinelandii: comparison to the complex from Escherichia coli. J Bacteriol 176, 4177-4181.

Krasnoselskaya, I., Arutjunjan, A. M., Smirnova, I., Gennis, R. B. \& Konstantinov, A. A. (1993). Cyanide-reactive sites in cytochrome bd complex from Escherichia coli. FEBS Lett 327, 279-283.

Lemieux, L. J., Calhoun, M. W., Thomas, J. W., Ingledew, W. J. \& Gennis, R. B. (1992). Determination of the ligands of the low-spin haem of the cytochrome $o$ ubiquinol oxidase complex using sitedirected mutagenesis. J Biol Chem 267, 2105-2113.

Longmuir, I. S. (1954). Respiration rate of bacteria as a function of oxygen concentration. Biochem J 57, 81-87.

Lundsgaard, J. S., Grolund, J. \& Degn, H. (1978). Error in oxygen measurements in open systems owing to oxygen consumption in the unstirred layer. Biotechnol Bioeng 20, 809-819.

Maniatis, T., Fritsch, E. F. \& Sambrook, J. (1982). Molecular Cloning: a Laboratory Manual. Cold Spring Harbor, NY: Cold Spring Harbor Laboratory.

Markwell, M. A. K., Haas, S. M., Bieber, L. L. \& Tolbert, N. E. (1978). A modification of the Lowry procedure to simplify protein determination in membrane and lipoprotein samples. Anal Biochem 87, 206-210.

Paget, T. A., Jarroll, E. L., Manning, P., Lindmark, D. G. \& Lloyd, D. (1989). Respiration in the cysts and trophozoites of Giardia muris. $J$ Gen Microbiol 135, 145-154.

Poole, R. K. (1983). Bacterial cytochrome oxidases: a structurally and functionally diverse group of electron-transfer proteins. Biochim Biopbys Acta 726, 205-243.
Poole, R. K. (1994). Oxygen reactions with bacterial oxidases and globins: binding, reduction and regulation. Antonie Leeuwenboek 65, 289-310.

Poole, R. K. \& Chance, B. (1981). The reaction of cytochrome $o$ in Escherichia coli $\mathrm{K} 12$ with oxygen. Evidence for a spectrally and kinetically distinct cytochrome 0 in cells from oxygen-limited cultures. J Gen Microbiol 126, 277-287.

Poole, R. K. \& Chance, B. (1995). Oxidase names: to ' 3 ' or not to '3'? Microbiology 141, 752-753.

Poole, R. K. \& Williams, H. D. (1987). Proposal that the function of the membrane-bound cytochrome $a_{1}$-like haemoprotein (cytochrome b-595) in Escherichia coli is a direct electron donation to cytochrome $d$. FEBS Lett 217, 49-52.

Poole, R. K., Waring, A. J. \& Chance, B. (1979). The reaction of cytochrome $o$ in Escherichia coli with oxygen. Biochem J 184, 379-389.

Poole, R. K., Scott, R. I. \& Chance, B. (1981). The light-reversible binding of carbon monoxide to cytochrome $a_{1}$ in Escherichia coli K12. J Gen Microbiol 125, 431-438.

Poole, R. K., Sivaram, A., Salmon, I. \& Chance, B. (1982a). Photolysis at very low temperature of CO-ligated cytochrome oxidase (cytochrome d) in oxygen-limited Eschericbia coli. FEBS Lett 141, 237-241.

Poole, R. K., Baines, B. S., Hubbard, J. A. M., Hughes, M. N. \& Campbell, N. J. (1982b). Resonance Raman spectroscopy of an oxygenated intermediate species of cytochrome oxidase $d$ from Escherichia coli. FEBS Lett 150, 147-149.

Poole, R. K., Kumar, C., Salmon, I. \& Chance, B. (1983a). The $650 \mathrm{~nm}$ chromophore in Escherichia coli is an oxygenated compound, not the oxidized form of cytochrome $d$ oxidase: an hypothesis. $J$ Gen Microbiol 129, 1335-1344.

Poole, R. K., Salmon, I. \& Chance, B. (1983b). The reaction with oxygen of cytochrome oxidase (cytochrome $d$ ) in Escherichia coli K12: optical studies of intermediate species and cytochrome $b$ oxidation at subzero temperatures. J Gen Microbiol 129, 1345-1355.

Poole, R. K., Williams, H. D., Downie, J. A. \& Gibson, F. (1989). Mutations affecting the cytochrome $d$-containing oxidase complex of Escherichia coli K12: identification and mapping of a fourth locus, cydD. J Gen Microbiol 135, 1865-1874.

Puustinen, A., Finel, M., Haltia, T., Gennis, R. B. \& Wikstrom, M. (1991). Properties of the two terminal oxidases of Escherichia coli. Biocbemistry 30, 3936-3942.

Rice, C. W. \& Hempfling, W. P. (1978). Oxygen-limited continuous culture and respiratory energy conservation in Escherichia coli. $J$ Bacteriol 134, 115-124.

Rothery, R. A., Houston, A. M. \& Ingledew, W. J. (1987). The respiratory chain of anaerobically grown Escherichia coli: reactions with nitrite and oxygen. J Gen Microbiol 133, 3247-3255.

Smith, A., Hill, S. \& Anthony, C. (1990). The purification, characterization and role of the $d$-type cytochrome oxidase of Klebsiella pneumoniae during nitrogen fixation. J Gen Microbiol 136, 171-180.

Timkovitch, R., Cork, M. S., Gennis, R. B. \& Johnson, P. Y. (1985). Proposed structure of haem D, a prosthetic group of bacterial terminal oxidases. J Am Chem Soc 107, 6069-6075.

Wood, P. M. (1984). Bacterial proteins with CO-binding $b$ - or $c$ type haem; functions and absorption spectroscopy. Biochim Biophys Acta 768, 293-317.

Received 23 August 1995; revised 14 November 1995; accepted 6 December 1995. 